Volume 2 Issue 2

December 2017

\title{
Out of alignment? A critical reflection on the student- teacher relationship in project-based paramedicine education.
}

John Rae PhD

Charles Sturt University, NSW, Australia

Alexander (Sandy) MacQuarrie BSc MBA PhD(c)

Charles Sturt University, NSW, Australia

\section{Recommended Citation}

Rae, J., and MacQuarrie, A. Out of alignment? A critical reflection on the student-teacher relationship in project-based paramedicine education. Irish Journal of Paramedicine. 2017 Dec; 2(2).

This is an Open Access article distributed under the terms of the Creative Commons Attribution-Non-Commercial-ShareAlike 4.0 International (http://creativecommons.org/licenses/by-nc-sa/4.0/),which permits use, distribution, and reproduction in any medium, provided the original work and any attributes thereof are properly cited, are distributed under the same licence, and that the work is not used for commercial purposes. 


\title{
Out of alignment? A critical reflection on the student-teacher relationship in project-based paramedicine education
}

\author{
John Rae PhD, Alexander (Sandy) MacQuarrie BSc MBA PhD(c) \\ 1. Charles Sturt University, School of Biomedical Science, Bathurst, NSW, Australia.
}

\section{Objectives}

This article draws on our experiences in project-based learning and in particular our experiences in facilitating a group of paramedicine students tasked with the responsibility of evaluating clinical simulation debriefing sessions. Using critical reflection as the research methodology, we unearthed and reworked our experiences in this project, especially the experiences of one of us, Sandy, who took on the role of project facilitator. The article identifies the importance of alignment between student and teacher in project-based learning and a set of principles are offered to guide and support this in project-based teaching. These principles include open communication and respect, the suspension of conventional belief, and reflection on professional practice.

Keywords: paramedic; teaching; debriefing; pedagogy; critical reflection.

\section{Introduction}

Paramedicine is a relatively new discipline in university-level education and many paramedic academics are in their first generation, often entering the university sector after full careers as paramedics. These paramedic academics draw from their own paramedic practice in teaching, using practical reasoning and intuition as they prepare their students for their future in the messy unpredictable world of work (1). Other strategies that paramedic academics use to prepare students for practice include the development and use of capstone subjects (2), problem-based learning (3) and clinical simulation (4). Project-based teaching is another strategy, although how this is practised by paramedic academics, and how it impacts on paramedic academics' relationships with their students, is unclear. Here, we critically reflect on a case of project-based teaching that involved a simulated mass casualty exercise and debriefing. The aims of the research were to:

1. Explore the student-teacher relationship and pedagogical traditions in the context of project-based teaching in paramedicine;

2. Create a set of principles to guide future project-based teaching.

\section{Simulated mass casualty exercise}

Five university undergraduate paramedic students in their second year of study participated in a two-day mass casualty exercise at a national army barracks. The event was hosted by a police counterterrorism security team and involved hostage taking, armed standoffs, 'car chases' and improvised explosive device bombings featuring casualties moulaged with realistic injuries. The students had the opportunity to test their treatment skills in scenarios lasting for twenty to thirty minutes and then participate in a short debriefing by paramedic academics and employed paramedics. Over one hundred police and fire personnel and seventy five casualty volunteers were involved in the exercise.

\section{Students' perceptions of debriefing}

At the end of the first day, the students had an opportunity to reflect on their experiences. They noted that the debriefing that followed the simulation was not entirely effective. They voiced concern about debriefing length (too short), type of feedback (some felt it was not productive) and the volume of calls that were debriefed (too many). Consequently, the format for the second day was modified taking turns, one student would lead the debriefing of the other students (under the supervision of academic paramedics). This resulted in fewer but longer debriefing sessions.

\section{An unexpected turn}

The simulation exercise and the experience of debriefing triggered the students' interest in the process of paramedic clinical simulation. This, albeit unexpectedly, prompted a student-led project about how to improve student paramedics' clinical simulation debriefing. It is noteworthy that these activities were not assessable items in the students' course.

Conversations with students, academics and peer tutors (senior paramedic students who tutor more junior paramedic students) supplemented a review of the literature on clinical debriefing. Nominal group technique and mind mapping were used to explore and record participants' experiences with debriefing and to create a series of recommendations. These recommendations were then presented to paramedic, nursing, health management and clinical science academics over three campuses of the university. The culmination of the students' experience was a poster presentation of the results to a national conference and the receipt of a national award for paramedic student leadership.

\section{Methodology and methods}

The research methodology was critical reflection. This originates from the reflective approach of educationalists 
Argyris and Schon (5) and draws on critical theories and postmodern ideas (6). Our concern was with 'unearthing fundamental assumptions (primarily those that are to do with power and connections between the individual and the social context)' (7), thus enabling, one of us, Sandy, to 'recognise values or beliefs that are fundamentally important' (7) to him. To achieve this, we took the following steps:

1. Sandy, as facilitator of the students' project, made mental notes about the students' work, the actions he took, and the outcomes that were achieved.

2. John, as interviewer, and Sandy, as interviewee, met to discuss the project-based learning activity in detail.

3. The meeting served to rework, through a process of deconstruction and reconstruction (6), Sandy's experiences of initiating and supporting the students' project.

4. The interview was recorded and transcribed verbatim.

5. The transcript was coded according to the phases of content analysis described by Elo and Kyngäs (8). That is, the transcript was read to obtain a 'sense of the whole' and then organised through a process of open coding. A code was considered a grouping of comments with a common theme.

\section{Results}

The data highlight tensions around the roles and responsibilities of students and their teacher, and also the student-teacher relationship, in project-based learning. This includes a contradiction between the notion of cognitive alignment, a term we borrow from Zollo (9), and the pedagogical tradition of constructive alignment (10). What also emerge are three principles for guiding project-based education in paramedic education contexts - the importance of suspending conventional belief, open communication and respect, and reflection on professional practice. We present these tensions, paradoxes and principles in a way that preserves much of the original conversation between us, especially Sandy's reflections.

\section{Alignment between student and teacher}

Reflecting on the students' presentation to academic staff, Sandy spoke of how the typical student-teacher relationship had been rearranged:

"all of a sudden I was watching people's body language around the room, and I ... thought wow, there's something really magical going on here ... So I was watching the back and forth, and I thought this is really something, there's a realignment going on here ... and here's the students showing us how they view it."

Put another way, the students became 'the teacher, the influencer ... well they did influence me; it influenced me in terms of my own learning and teaching, my own practices', Sandy said. This was foreign to Sandy's prior understanding of student and teacher roles: 'My supposition was the student -teacher relationship involve [d] an academic on one side and [on the other side is] a student who's probably younger and undergraduate ... But this absolutely changed'.

Sandy reflected on how the students presented the outcomes of their project to a room full of academics across various health-related disciplines, and how these students created a podcast about their project and wrote two articles for an Emergency Medical Services website. As Sandy said: 'that's when I was really starting to understand that things were very different with this project'. That is, the power differential between the students and the teacher was levelled. Relating this to the usual conventions of teaching, Sandy responded: 'There was enough leeway within the rules of learning and teaching that we could execute this project'. This is not to say that Sandy was unaware that his methods were novel and indeed untested: 'I was certainly of the expectation that it might not go well', he said. So how did Sandy manage this uncertainty? He said that it:

"took a blend of absolutely standing back a lot of the time and letting them form and norm and storm and all that sort of stuff, and have their fights and disagreements and then kind of pick the times that you have [to] come in, offer some mentorship, or simply listen, and then back off again. And then find resources."

This positioning of the teacher is an important point, as Sandy explains:

"Absolutely, you stay back. There are times that you
have to intervene if you think things are not where
they should be. And as it unfolded ... you can say
yeah, it's on track, no it's not on track, what am I
learning? What are they learning? ... This is working,
this is working, and the feedback keeps coming back-
keeps coming back yes, it's working, or it's working
the best way it can, then you just let it flow."

Sandy continued: 'How do I get ... my thoughts and ideas to align ... [with] theirs'? That is, Sandy did not seek alignment with predetermined subject objectives or assessment criteria, but with the learners, and those learners' varied and changing learning needs.

The questioning of assumptions about student-teacher relationship and of 'alignment' brought into focus three principles that guided Sandy, and which we hope will be useful for other paramedicine academics. The first principle is 'suspension of conventional belief'.

\section{Principle 1 - Suspension of conventional belief}

Conventional belief serves to guide practices, here teaching practices, but it can also delimit them. Sandy reflected on this:

"I have no idea what they're going to come up with, I have no idea ... I was thinking, they'll learn really well how to do a poster, and it'll help them, I think, in their professional practice. But they saw it as far more than that ... So part of it is knowing your own limitations ... in terms of the knowledge that's developing, and being open."

\section{Principle 2 - Open communication and respect}

Central to Sandy's approach to teaching was what he referred to as 'open communication and respect'. He explained:

"Underneath it all was the fact that we had a very good stream of communication between the group and myself ... and that goes back [to] rapport. And underneath the rapport is a mutual respect ... they could float an idea and not think that it was going to be shut down, and so could I. So, what makes it work is the ability to take risk, the ability to communicate at 
least in the beginning what you think might be some possible outcomes of whatever happens to be in front of them, and to hear what they think. [It's] a communication thing."

Asked if he was really talking about listening, Sandy expanded: 'really hear - really listen - really watch'. Of course, that does not mean that Sandy ceased to guide students' learning, as he illustrates here:

There was an instance where one of the group members had kind of gone off on his own and was attempting to finish the project without the input from the other four. And at that point he needed very measured guidance and so we had him in for a conversation and I can remember him saying 'I want to do this and I want to do this, and then I'm going to do this', and I said 'I note you're speaking in the singular, where is the rest of your team'? And there was this pause, and then from that point on, there was a change.

Principle 3-Reflection on professional practice

What is at issue here is Sandy's teaching practice and the confrontation of this with paradoxes (11). How did Sandy respond? He said:

"For me to understand what they were trying to do, I had to reflect on it a lot, you know. They're going way past [where] I thought they were going to go, so I had to reflect and reflect and reflect... And if [I] want to say one of the things that's changed ... is my ability to reflect on practice, and the ability to change practice because of that."

As can be seen from the above quotation, Sandy worked by continually reflecting on his teaching practice, and less, as has been noted, on the rules of that practice. He agreed:

"Yeah, I like to explore the edges ... it's not a matter of being able to run a cardiac arrest competently, necessarily, that's one of it, but it's the ability for them to take on something that's completely outside of [their] comfort zone, figure out where to get the resources, and to execute it, and to reflect ... to watch the students over a 12-month period mature as a group and how they present themselves and their palpable outputs that they've had has been amazing. So their professional practice has deepened even before they've joined their profession."

\section{Discussion}

This project resulted in a series of outcomes including improvement in the process of debriefing after clinical simulation, students' presentation of a poster at a national conference, and them receiving a national award for paramedic student leadership. What the students took from their project-based learning experience exceeded what most paramedic curriculum developers would likely hope for, including advanced communication, negotiation, organisation and judgement skills. These are some of the skills required of an expert paramedic. We acknowledge that there were many influences on these outcomes and on the success of the project more generally. For instance, all five students were experienced peer tutors at the university, were routinely involved in simulations requiring a degree of debriefing afterwards, and so had a higher-than-expected level of motivation to participate in the project. Nevertheless, we believe that the key influence was the decentred teacher, highlighted when Sandy spoke about there being times when his intervention was required, and times when it was not required. What underlies this, according to Sandy, was the 'levelled' power differential between the students and teacher. Decentring, as originally described in learning theory by Piaget and reported on by Tauscher et al in 2015 is 'the teacher's ability to effectively focus on student thinking, and illustrate its usefulness in making instructional decisions that are informed by and advance student thinking' (p. 5) (12). It can also be argued that this occurred out of Sandy's cognitive alignment with his students as Sandy's bond with his students advanced. This is what we refer to as 'cognitive alignment' (9). Supporting this was Sandy's suspension of conventional belief, open communication and respect, and also a deep reflection on his professional practice. Indeed, this notion of 'practice', or more correctly 'practice theory', is a useful lens through which to further examine Sandy's work as a paramedic academic.

The practices and conventions of teaching were challenged in this project. Sandy was able to see 'leeway' in these conventions or rules. It can even be argued that Sandy was 'thinking outside and beyond the rules' of teaching practice, a phrase that Edwards-Groves (13) used in specific reference to practice theory. Schatzki (14) wrote that rules are what 'enjoin, direct, or remonstrate people to perform specific action' - that is, to enact a practice. Green even suggests that these 'rules emerge retrospectively' (15). Sandy was going outside the rules, and arguably, making them. Of this, Sandy said: 'the quality of the information might not be good, and that in the end, it may not contribute to their learning experience or ours. I was prepared for that; it didn't happen'.

This is reminiscent of how Huxham (16) used the metaphor of 'mountaineering' to describe teaching. Students and teachers co-navigate; they work with:

"[N]atural features of the rock, choosing a way which balances challenge and feasibility. The most highly prized routes are 'natural lines' distinguished by their aesthetic simplicity; gullies, cracks and buttresses offered up by the mountain as compelling temptation. Such lines demand commitment. Escape routes are few, the climbing is sustained, without meandering slack pitches, and the key moves are often difficult to reverse. In contrast 'contrived' routes feel fragmented and artificial; they may bring fun and technical challenge, but are often easy to forget and have multiple possible escape points" (p. 530).

Huxham and his colleagues' (16) metaphor for this more contrived and traditional approach to teaching, which emphasises constructive alignment, is surveying or engineering. Sandy's concern for 'alignment', that is, cognitive alignment, is arguably just as important as the alignment between learning objectives, assessments, and so forth. This gets to what Kemmis and his colleagues (17) wrote about teaching and:

"[T]reat[ing] teaching not only instrumentally, as a means of learning, but also as a practical creative and critical practice ... [This] invites us to re-frame our contemporary understanding of teaching: to see 
teaching as a practice of initiating students into practices" (p. 100)

The principle 'Suspension of conventional belief' and especially Sandy's openness to uncertainty brings to mind the Aristotelian concept of aporia - the 'confrontation in one's own practice with unresolvable problematics' (12). Green writes that this is at the heart of professional practice, and relates to, for instance, clinical judgement, which is responded to by 'practical wisdom' or 'phronesis', something that Green considers 'marks the work of - organic professionals' (11).

Sandy referred to the importance of reflecting on the learning experiences of students, and also students' ability to reflect on their unfolding project. One might argue, then, that Sandy's students were becoming what Rooney (1) and her colleagues would call 'agile'. Could it be that, here, practice informed pedagogy? This would be the case if one accepts what Lee and Dunston wrote, that practice theory: 'allows us to begin to understand what might be required in curriculum and health professional education to foster creative improvisation and innovation in response to the changing demands of new practice configurations' (p. 491) (18). Syllabus and curriculum, and associated with that, constructive alignment, is still required, of course. At the course level, where objectives are necessarily broad and farreaching (at our institution, course objectives are devolved to more specific subject objectives), there was constructive alignment. For example, the course-level objectives of the paramedicine program that Sandy taught in makes reference to 'supporting continuous professional development', which is something that our students well and truly covered if one is to consider their preparedness to enter the paramedic profession as confident, autonomous lifelong learners.

\section{Conclusion}

The transformation of a student experience in mass casualty simulation into a significant learning experience for students changed the way in which a paramedic university department conducted debriefing. This set the stage for a journey into decentred learning and an understanding of the value of this.

Project-based education, as described here, offered a rich learning experience for both the students and Sandy; it was an especially positive experience that came about through involved experimentation rather than deliberate thinking (15). To this, Sandy adds:

The result of the teaching practice has been very satisfying, and I think for an academic, sometimes there's days that we get pretty frustrated at what we do. Sometimes it's because the rules that we operate in are ... whatever, so this tempered that for me and it gave me a real good feeling about why I'm here and what I'm doing ... I've got this wonderful project and all things that came from it. So it makes me very optimistic. Now, is it transferrable from my practice to another academics? Well, maybe this paper and this presentation will be part of it.

Paramedic education and pedagogy continue to develop, of course, and the principles unearthed in this project - open communication and respect, the suspension of conventional belief, and reflection on professional practice will hopefully add to this development, especially in the area of project-based learning. These principles may even be applied to other disciplines that share some of the characteristics of paramedicine education.

Looking at this case through a practice-theoretical lens has illuminated some issues raised about 'rules', taking risks and working with uncertainty, and initiating students into practices, and these may be a useful topics in future research.

Finally, we suggest that critical reflection is a hallmark of professional practice and a tool that paramedics and paramedic educators should consider. The 'real world' or practical experiences that paramedic academics bring to their teaching can thus more fully enrich their students' learning experiences.

\section{References}

1. Rooney, D., Hopwood, N., Boud, D., \& Kelly, M. The Role of Simulation in Pedagogies of Higher Education for the Health Professions: Through a Practice-Based Lens. Vocations and Learning, 2015; 8(3) 269-285.

2. Thompson J., Grantham, H., \& Houston, D. Paramedic capstone education model: Building work ready graduates. Australasian Journal of Paramedicine. 2015; 12(3).

3. Dixon, M., Keane, F. \& Taylor, A. Paramedic Educationis dynamic Problem Based Learning the way forward? Irish Journal of Paramedicine. 2016; 1(2).

4. Abelsson, A., Rystedt, I., Suserud, B.O. \& Lindwall, L. Learning by simulation in prehospital emergency care-an integrative literature review. Scandinavian Journal of Caring Sciences. 2015; 30(2) 234-40.

5. Argyris, C., \& Schon, D. A., Theory in practice: Increasing professional effectiveness. 1974; Jossey-Bass.

6. Morley, C., Critical reflection as a research methodology. In Knowing Differently: Arts-Based and Collaborative Research Methods. 2008; Nova Science Publishers, 265-80.

7. Fook, J. Developing critical reflection as a research method. In J. Higgs, A. Titchen, D. Horsfell, \& D. Bridges (Eds.), Creative Spaces for Qualitative Researching 2011; Springer 55-64.

8. Elo, S., \& Kyngäs, H. The qualitative content analysis process. Journal of Advanced Nursing, 2008; 62(1), 107-115. 9. Zollo, M., Minoja, M., Casanova, L., Hockerts, K., Neergaard, P., Schneider, S., \& Tencati, A. Towards an internal change management perspective of CSR: evidence from project RESPONSE on the sources of cognitive alignment between managers and their stakeholders, and their implications for social performance. Corporate Governance: The International Journal of Business in Society, 2009; 9(4) 360 .

10. Biggs, J. B., \& Tang, C. Teaching for quality learning at university: What the student does. 2011; McGraw-Hill Education.

11. Green, B. Introduction. In B. Green (Ed.), Understanding and researching professional practice. 2009; Sense Publishers, 1-18.

12. Teuscher, D., Moore, K., \& Carlson, M. Decentering: A construct to analyze and explain teacher actions as they relate to student thinking. Journal of Math Teacher Education. 2015;19(5) 433-56.

13. Edwards-Groves, C., Gray, D., Kemmis, S., \& Smith, T. (2008). Developing praxis and reflective practice in preservice teacher education. In S. Kemmis \& T. Smith (Eds.), Enabling praxis: Challenges for education 2008; Sense Publishers 85-107.

14. Schatzki, T. The site of the social: A philosophical account of the constitution of social life and change. 2002; Penn State Press.

15. Green, B. (2011). Research, Practice, Emergence; or, 
Emergent methodologies in education research. Paper presented at the Summer Institute in Qualitative Research. 2011: Manchester.

16. Huxham, M., Hunter, M., McIntyre, A., Shilland, R., \& McArthur, J. Student and teacher co-navigation of a course: Following the natural lines of academic enquiry. Teaching in Higher Education, 2015; 20(5), 530-541.

17. Kemmis, S., Wilkinson, J., Edwards-Groves, C., Hardy, I., Grootenboer, P., \& Bristol, L. Teaching: Initiation Into Practices Changing Practices, Changing Education 2014; Springer. 93-126

18. Lee, A., \& Dunston, R. Practice, learning and change: Towards a re-theorisation of professional education. Teaching in Higher Education, 2011; 16(5) 483-494.

Author contributions: All authors contributed to the writing and final editing of the manuscript.

Source of support/funding: None.

Conflict of interest: No conflicts of inter est were declared.

Provenance and review: Not commissioned, peerreviewed.

This is an Open Access article distributed under the terms of the Creative Commons Attribution-Non-Commercial-ShareAlike 4.0 International (http:// creativecommons.org/licenses/by-nc-sa/4.0/), which permits use, distribution, and reproduction in any medium, provided the original work and any attributes thereof are properly cited, are distributed under the same licence, and that the work is not used for commercial purposes. Content copyright remains with the authors, who grant the IJP a licence to reuse and distribute. 